\title{
Topic Study Group No. 24: History of the Teaching and Learning of Mathematics
}

\author{
Fulvia Furinghetti, Alexander Karp, Henrike Allmendinger, \\ Johan Prytz and Harm Jan Smid
}

The Topic Study Group on the history of the teaching and learning of mathematics was formed in 2004 at ICME-10. Its work reflects the growing interest in the history of mathematics education. At ICME-13 in Hamburg, this TSG had more participants than in previous years, but the procedure at the main meetings followed established tradition-short reports were heard, after each of which the speaker could answer some questions. Before turning to a discussion (necessarily very brief) of the contents of the reports, a few words must be said about the beneficial innovations that set apart the 2016 conference.

The first of them was the publication of a booklet, History of mathematics teaching and learning. Achievements, Problems, Prospects (Springer, 2016), prepared by Alexander Karp and Fulvia Furinghetti in discussion with the other members of the team. Hopefully, this booklet offers researchers (first and foremost, beginning researchers) useful bibliographic information, and also lists a number of areas in which scholarly work is being conducted in different countries. Another innovation was the introduction of so-called "Oral Communications," that is, additional meetings at which more presentations were heard. Along with poster presentations, they gave participants an opportunity to form a better understanding of what is being studied by historians of different countries' mathematics education. Since these presentations cannot be discussed in detail here, we restrict ourselves to listing the authors of the studies that were presented (names of presenters in

Co-chairs: Fulvia Furinghetti, Alexander Karp.

Team members: Henrike Allmendinger, Johan Prytz, Harm Jan Smid.

F. Furinghetti

University of Genoa, Genoa, Italy

e-mail: furinghetti@dima.unige.it
A. $\operatorname{Karp}(\square)$
Teachers College, Columbia University, New York, USA
e-mail: karp@tc.columbia.edu; apk16@columbia.edu
(C) The Author(s) 2017
G. Kaiser (ed.), Proceedings of the 13th International Congress on Mathematical
Education, ICME-13 Monographs, DOI 10.1007/978-3-319-62597-3_51 
boldface): Eisso Johannes Atzema; Eliete Grasiela Both, Bruna Carnila Both; María Teresa González Astudillo, Myriam Codes Valcarce; Günter Graumann; Zohre Ketabdar, Maryam Ketabdar; María José Madrid; Alexander Maz-Machado, Carmen León-Mantero, Carmen López; Marvin Roberto Mendoza, Luis Armando Ramos; Nicola M.R Oswald, Nadine Benstein; Irene Papadaki; Athanasios Gagatsis, Elena Kiliari; Emily Timmons Hamilton Redman; Ildar Safuanov.

Finally, it must be noted that plans are underway to publish the results of the work of the TSG as a collection of papers, in which selected studies by the participants will be presented in greater detail than they were either during oral presentations or in electronic publications on the conference website. All of these innovations are very significant.

To turn now to the presentations heard at the main meetings, we would like to give special mention to the report of invited speaker Gert Schubring, Patterns for Studying the History of Mathematics Education: A Case Study of Germany. Devoted to the history of German mathematics education, the report went beyond this framework, since it possessed considerable methodological significance. It emphasized that the very subject of the history of mathematics education is multidisciplinary by nature. It is impossible to understand what went on in the teaching of mathematics without taking into account what was taking place in social history. The presenter demonstrated the importance of such an approach, showing how various systems of mathematics education formed in the German states of the nineteenth century, reflecting religious and political differences in their histories.

Probably the most popular period in terms of the number of presentations devoted to it this time was New Math (to use this American term to denote the period of reforms that took place in different countries and usually under different names). This once again indicates the importance of what happened during this period in the sixties and seventies of the last century including those cases about which accepted opinion is that the reforms failed. In a presentation titled Royamount-Proposals of Arithmetic and Algebra Teaching for the Lower Secondary School Level, Kristin Bjarnadóttir examined the influence of the famous seminar in Royamount on teaching in Icelandic, and more broadly, Scandinavian elementary schools. Changes in instruction in another subject and in another country (Brazil and in part France) were the topic of Elisabete Zardo Burigo's report Real Numbers in School: 1960s' Experiments. Dirk De Bock and Geert Vanpaemel in their report on Early Experiments with Modern Mathematics in Belgium addressed the history of teaching in elementary school and even kindergarten, and the corresponding preparation of teachers, when Belgium became one of the leaders of the reform movement. Finally, Johan Prytz, presenting a report titled New Math for Big Education, Old Math for Small Education. A Study of Different Ways to Reform School Mathematics, analyzed various teaching materials to investigate broader issues connected with the development of reforms in Sweden (including the question of whether it is correct to believe that the reforms failed).

Also strongly connected to this topic was the presentation by Gabriella Ambrus, Andreas Filler, Ödön Vancsó, Functional Reasoning and Working with 
Functions in the Mathematics Teaching Tradition in Hungary and Germany, which naturally devoted attention to the New Math period, when functions once again began receiving greater attention than they had during the preceding period. Comparing the teaching of specific subjects in different countries is a fruitful idea that has been often developed in the past.

The study of teaching materials (first and foremost, textbooks) and the biographies of their authors is one of the principal areas of research in the history of mathematics education. In Hamburg, this topic was addressed, on the basis of Spanish materials, by the reports of Antonio M. Oller-Marcén, Vicente Meavilla, Arithmetic in the Spanish Army at the End of the Nineteenth Century. The Works of Salinas and Benitez, and in part by Miguel Picado, Luis Rico, Bernardo Gómez, The Metrological Reform in the Spanish Educational System in the Nineteenth Century: Who Were the Authors of the Textbooks?

Jenneke Krüger's paper Frans van Schooten Sr: Dutch Mathematics for Engineers, Leiden, 1611-1645 addressed related issues, although its focus was not a textbook, but surviving lecture plans. The most significant aspect of this presentation was probably that the materials studied are not of comparatively recent provenance, but date back to the seventeenth century, from which many fewer documents survive, and which in addition have by no means been everywhere thoroughly studied. It is to be hoped that the seventeenth and eighteenth centuries will attract more attention from researchers in the future.

Textbooks from the period that predates even the seventeenth century are the focus of Alexei K. Volkov's paper Didactical Function of Images of Counting Devices in Chinese Mathematical Textbooks. This study can also be said to address the history of using technology in mathematics education (which of course must not be thought of as beginning in the twentieth century).

Harm Jan Smid presented a report on Becoming a Mathematics Teacher in Times of Change, devoted to the biography of a Dutch teacher born in 1778, who lived during a time of upheavals, and whose life demonstrates the changes that took place in society and consequently in mathematics education as well. The biographies of teachers - although teachers living in a different country and during a different time-were also the subject of the report Russian Mathematics Teachers, 1830-1880: Several Examples by Alexander Karp. This paper summed up the author's archival research on the biographies of teachers mainly from St. Petersburg, which shed light on the formation of mathematics teachers as a professional group. Also connected with this topic was the report by Fulvia Furinghetti and Annamaria Somaglia The Professionalization of Italian Primary Teachers through a Journal Issued at the Beginning of the Twentieth Century, which addressed the journal Bollettino di Matematiche e di Scienze Fisiche $e$ Naturali and its role in the formation of Italian elementary mathematics education.

Reforms in mathematics education were not, of course, limited to the New Math period. Probably one of the most successful examples of reform was the Meiji period in Japan, which was the subject of a report by Marion Cousin, The Revolution of Mathematical Teaching during the Meiji Era (1868-1912). The transfer, or more precisely, the adaptation of foreign achievements in mathematics 
education may be said to be one of the most recurrent and prominent topics in its history. Successful examples may be considered important not only for historians, but also for practitioners of mathematics education.

We conclude this brief inventory with the presentation of Sethykar SamAn, History of Mathematical Instruction in Colonial Cambodia, which is of particular interest not least because its subject has received extremely little attention, and because of the methodological difficulty of such a study in view of the almost complete destruction of possible sources during the period of Pol Pot's dictatorship. Meanwhile, the study of the history of mathematics education in Cambodia, and more broadly, the study of the history of education in other colonial or semi-colonial countries, is of enormous interest, if only because it combines many of the issues and topics mentioned above. This kind of research must definitely be continued.

As may be seen from what has been said, the four 90-min meetings that the TSG had at its disposal were quite packed. No less packed is the program for the future development of our field of research, which was the focus of the meetings in Hamburg. The problem of collecting and publishing materials on the history of mathematics education, and even more importantly, the problem of interpreting them as part of the social history of each country and of the whole world, seem especially important today, during our own period of significant changes in education as a result of both technological and social transformations. The work of the TSG at the Hamburg conference was a useful step toward the solution of these problems.

Open Access Except where otherwise noted, this chapter is licensed under a Creative Commons Attribution 4.0 International License. To view a copy of this license, visit http://creativecommons. org/licenses/by/4.0/.

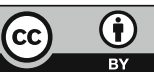

